R. História, São Paulo, 120, p.121-133, jan/jul. 1989.

\title{
O ROUBO DE ESCRAVOS NO RIO DE JANEIRO E O TRÁFICO INTERNO PARALELO; 1808-1850*
}

\author{
Luiz Carlos Soares**
}

RESUMO: A documentação policial da Côrte na primeira metade do século passado evidencia a frequiência de um comércio ilícito de escravos roubados e revendidos para as províncias vizinhas. Delineia-se a par do tráfico internacional de contrabando, um comércio marginal a preços bem menores, controlados $\mathrm{cm}$ sua maioria por ciganos e seus intermediários. Também envolvia capitães de mato ou quadrilhas muito bem organizadas. Era um meio de fornecer mão-de-obra mais barata a pequenos proprietários. Por vezes este comércio envolvia libertos em alforria condicional, evidenciando uma circulação clandestina de parentes escravos.

UNITERMOS: tráfico de escravos, contrabando, roubos, capitães de mato, libertos condicionais.

A documentação da polícia da Côrte para a primeira metade do século XIX nos revela um fenômeno até agora pouco mencionado pelos historiadores: a grande quantidade de roubos de escravos praticados na cidade do Rio de Janeiro ${ }^{1}$. Na medida em que o tráfico negreiro africano aumentava o seu volume e despejava na cidade grandes levas de cativos ${ }^{2}$, os roubos da pro-

* Este trabalho é uma versão de parte do Capítulo II \{"The slave market in nineteenth-century Rio de Janeiro") da tese de doutoramento defendida em janeiro de 1988 no University College of London (Inglaterra), sob o título Urban slavery in ** nineteenth-century Rio de Janeiro.

Departamento de História- ICHF/UFF.

1 Entre os trabalhos conhecidos, que citam a freqüência dos roubos de escravos, estão os de KARASCH, Mary C., Slave life in Rio de Janeiro, J808-J850. Dissertação de Doutoramento, Universidade de Wisconsin, 1972. p. 367-368; e ALGRANTI, Leila Mezan. O feitor ausente. Estudo sobre a 'escravidão urbana no Rio de Janeiro, 1808-1821. Dissertação de Mestrado, Universidade de São Paulo, 1983. p. 76-79.

2 Dos 1.500,000 escravos que teriam entrado no Brasil entre 1800 e 1850, aproximadamente 900.000 deles foram desembarcados no Rio de Janeiro, Cf. CONRAD, Robert E, . Tumbeiros. O tráfico de escravos para o Brasil Tradução de Elvira Serapicos. São Paulo: Brasiliense, 1985. p. 43; e KARASCH, Op. cit., p. 106. 
SOARES, Luiz. Carlos. O roubo de escravos no Río de Janeiro e o tráfico interno paralelo: 1808-1850.

príedade humana cresciam assustadoramente, levando aos senhores e às autoridades policiais muitas preocupações. Dessa forma, agindo isoladamente ou em grupo, muitos indivíduos participaram, fora dos limites estabelecidos pelas leis vigentes, das especulações comerciais com o elemento cativo, pois os escravos roubados eram posteriormente levados para fora da cidade e vendidos para fazendeiros ou pequenos lavradores. Impossibilitados que estavam de concorrer com os grandes traficantes estabelecidos na cidade, os ladrões de escravos fizeram da sua atividade uma alternativa "paralela" ou "marginal" ao comércio de carne humana no Rio de Janeiro.

Embora não tivesse a mesma dimensão do comércio "legal" de escravos, este comércio "marginal" possibilitou a transferência para fora da cidade de um grande número de cativos. Muitos foram os indivíduos pilhados em flagrante acoitando, conduzindo ou vendendo escravos roubados, mas é provável que um numero muito maior de ladrões, agindo com grande desembaraço, jamais teve as suas atividades descobertas ou reveladas pela polícia. Talvez alguns ladrões tenham agido até mesmo associados a negociantes de escravos que se utilizavam dos métodos mais inescrupulosos, A aprovação de uma postura pela Câmara Municipal da Côrte em 1838, que impunha aos senhores que vendiam escravos o pagamento de um depósito restituivel e a fiscalização das casas de compra c vencia de cativos pelos funcionários municipais, revelava muito bem a preocupação das autoridades em face do aumento dos roubos e das transações ilegais de escravos. Um grupo de grandes negociantes, ao protestar contra esta postura que, segundo eles, era um entrave "à ampla liberdade do comércio garantida na Constituição", procurou afastar as suspeitas sobre a sua categoria, confirmando porém a freqüência dos roubos praticados por "pessoas ocultas". Eis a sua própria justificativa:

"(...) a experiência tem mostrado, que os roubos e danos que cotidianamente há em escravos não são feitos nem tolerados pelos negociantes de casa aberta, porque como casas públicas nelas não podem haver malefícios, que não sejam de pronto descobertos, e por isso os malfeitores deste gênero são sempre pessoas ocultas e não negociantes de casa aberta, dos quais até o presente ainda nenhum foi levado ao juiz" ${ }^{3}$.

Apesar desta declaração de inocência, é provável que traficantes de "casa aberta" tenham participado como receptadores ou agenciadores de

3 Cf. Arquivo Geral da Cidade do Rio de Janeiro, Escravos ao ganho e escravidão: 1833-1841, Códice 6-1-43. 
R. História, São Paulo, 120, p.121-133, jan/jul. 1989.

roubos de escravos, mas conseguiram manter-se "ocultos". Porém, menos sorte tiveram muitos capitães-de-mato (em grande número negros e mulatos libertos) e ciganos que foram flagrados pela polícia vendendo escravos furtados.-Tanto os capitães-de-mato como os ciganos eram conhecidos pela população da cidade como notórios ladrões de escravos e eram sempre os primeiros a ficar sob suspeita, quando algum roubo era denunciado ou se fazia público.

Os capitães-de-mato tinham também a "má fama", como relatava Frederico Burlamaqui em 1837, de prenderem e esconderem escravos "por muitos dias a título de fugidos", para exigir dos senhores o pagamento da tomadla, ou seja, a gratificação pela sua captura. Mas, de acordo ainda com Burlamaqui, as mais lucrativas "especulações" dos capitães-de-malo eram mesmo os roubos de escravos, que lhes possibilitavam um rendimento muito maior do que as prisões e ocultamentos destes para recebimento das tomadias. Em 1821, a polícia da Côrte prendeu oito capitães-de-mato, encontrando em seu poder escravos roubados para posterior venda. Em 1823, foi a vez do capitão-de-mato Apolinário da Costa Gonçalves ser preso em sua casa, "no sítio dos Cajueiros junto à Igreja de S. Ana", sendo com ele encontrados "Izabel Maria, parda forra, e sete escravos de diversos senhores (...), que ele conservava em tronco (...) com o fim de os vender para fora da terra", castigando-os constantemente com o objetivo de intimidá-los "para com mais segurança conseguir o fim que pretendia" ${ }^{4}$.

Existiam também aqueles capitães-de-mato que agiam articulados aos ciganos, como era o caso de Jacinto Dutra do Nascimento, preso cm 1815 porque prendeu um escravo fugido e o vendeu posteriormente ao cigano $\mathrm{Fe}$ lizardo da Bela-Cruz. O cigano neste caso funcionou como receptador e revendedor de escravos roubados. Na ocasião da prisão do capitão-de-mato, a polícia encontrou em seu poder outros escravos, presumivelmente roubados .

Os ciganos tinham fama de grandes ladrões, principalmente de escravos e animais, mas na cidade do Rio de Janeiro sua especialidade foi o roubo ou a interceptação daqueles primeiros. Em 1817, o Intendente de Polícia Paulo

4 Cf. BURlamaQui, Frederico Leopoldo Cezar. Memoria analytica a cerca do commercia $d$ escravos e a cerca dos malles da escravidão domestica. Rio de Janeiro: Typographia Commercial Fluminense, 1837. p. 83; e Arquivo Nacional do Rio de Janeiro (doravante denominado ANRJ), Polícia: oflclos $e$ ordens: 1819-1823. Códice 330 - Volumes II e III.

5 Cf. Ibidem, 1819-1823. Códice 329, Volume III. 
SOARES, Luiz Carlos. O roubo de escravos no Rio de Janeiro e o tráfico interno paralelo: 1808-1850.

Fernandes Vianna, em carta ao Juiz de Crime da Sé (depois freguesia do Sacramento), falava do aumento dos roubos de escravos praticados por ciganos e das técnicas que estes utilizavam:

"Havendo-se percebido de tempos a esta parte um grande extravio de escravos das casas de seus Senhores, sem se entender o modo porque se fazia, pude conseguir por muitas averiguações, que era por meio de furto de ciganos, que eles desapareciam das ruas andando em serviço de seus Senhores; uns induzidos, outros enganados a troco de ganharem alguma coisa em recados e serviços a que fingidamente os chamavam, e depois abafado e imediatamente tirados da cidade por terra firme, ou para outra banda, e ali vendidos, e tudo isto por ciganos, e seus agentes, o que me obrigou a dar muito apertadas ordens para serem procurados e perseguidos por todos os Distritos" 6 .

Em conseqüência das ordens do Intendente de Polícia, alguns ciganos foram presos naquele ano, como aconteceu a Bento Soares da Rocha, que levara dois escravos roubados para Irajá, freguesia de fora da cidade. Este cigano teve seus bens confiscados (cavalos e bestas) e os escravos foram soltos e entregues a seus senhores. Segundo a policia, ele ainda atuava em cumplicidade com o cigano João da Costa, que lhe forneceu um escravo para ajudar no roubo. Entretanto, outros ciganos, além de João da Costa, conseguiram escapar à ação policial, como foi o caso de Bernardo José de Souza, em cuja casa foram encontrados cinco escravos (quatro homens e uma mulher), além de Manoel Benguela, escravo do cigano foragido, acusado de "ser o condutor dos escravos furtados" 7 .

Em nada adiantou a ação da polícia em 1817, pois pouco tempo depois os ciganos se reorganizaram e voltaram novamente ao roubo de escravos, agindo com a maior desenvoltura durante as décadas seguintes. Em 1829, a polícia conseguiu prender três dos mais importantes ciganos ladrões de escravos, que agiam não só na cidade do Rio de Janeiro, como também nas províncias vizinhas. Os ciganos presos eram Joaquim Alves Saião, Antônio da Costa e João da Costa, "bem conhecidos por seus costumados roubos e mortes". Os dois primeiros fora presos conduzindo quatro escravos roubados para fora da Côrte, enquanto que João da Costa, cujas atividades eram conhecidas pela política desde 1817, foi preso após ter sua casa revistada e nela serem achados dois escravos roubados:

6 Cf. ANRJ, Op. cit., 1815-1820, Códice 329, Volume IV.

7 Cf. Ibidem. 
R. História, São Paulo, 120, p.121-133, jan/jul. 1989.

"(...) um negro de nome Felipe Benguela do Brigadeiro Albino Gomes Guerra d'Aguiar, quando a vender laranjas foi chamado pelas filhas do dito cigano a pretexto de comprarem quitanda e apenas entrou lhe fecharam a porta e o conduziram ao quarto de costume e uma negra boçal que vendi» água chamadas pelas sobreditas filhas com quem houve iguais procedimentos" ${ }^{8}$.

Além dos capitães-de-mato e ciganos, muitos escravos e libertos tam bém se envolveram nos roubos de cativos, agindo independentemente ou então a serviço de outros, como aliciadores ou condutores dos escravos furtados. Até mesmo aqueles que passavam ou tinham passado pelos horrores do cativeiro eram atraídos pelo comércio marginal de escravos, procurando nele a obtenção de alguma remuneração que lhes possibilitasse enfrentar as duras condições de sobrevivência. Convém notar que alguns escravos participaram de roubos de indivíduos da sua própria condição praticamente obrigados por seus senhores, como o escravo do cigano João da Costa, emprestado ao cigano Bento Soares da Rocha para lhe auxiliar num roubo, ou Manoel Benguela, escravo do cigano Bernardo José de Souza, que ajudava a conduzir para fora da cidade os cativos roubados por seu senhor.

Entretanto, muitos cativos se envolveram no roubo de seus semelhantes espontaneamente, sem a pressão de seus senhores, aproveitando-se da sua liberdade de movimento pela cidade e do convívio e íntimo conhecimento que tinham com outros cativos, para atraí-los e furtá-los. Em 1822, o mulato Maximiliano, escravo de Angélica de Paiva, foi preso juntamente com uma companheira, a preta Floriana, por serem encontrados na casa desta, em Mataporcos, dois escravos novos roubados pelo mulato. Em 1827, era a vez de Domingos Monjolo, escravo de Francisco Nunes, ser preso por um capitão-de-mato e conduzido para a cadeia, acusado de roubar escravos e vendê-los a ciganos, que neste caso atuavam como receptores ${ }^{9}$.

Já o escravo Pascoal, de um certo Senador Aguiar, atuava como aliciador a serviço de um preto de nome Antônio Guedes Pinto, que tinha uma "casa de quitanda na rua dos Herradores n. 21 ". Em 1833, o escravo Pascoal e o liberto quitandeiro foram presos pela policia devido às denúncias de um crioulo liberto de nome Antônio e dos escravos Candido Cassange e Manoel Benguela, que declararam à policia serem constantemente aliciados pelo escravo Pascoal e por um outro escravo que tinha se enforcado, chegando a levá-los para a casa do quitandeiro "com promessa de que iam ficar libertos

8 Cf. ANRJ, Op. cit., 1826-1833, Códice 330, Volume V.

9 Cf. ANRJ, Op. cit., Códice 330, Volume IV. 
SOARES, Luiz Carlos. O roubo de escravos no Riu de Janeiro e o tráfico ínterno paralelo: 1808-1850.

no fim de um ano de serviço". Os dois escravos e o liberto conseguiram fugir da casa de Antônio Guedes Pinto e foram imediatamente fazer denúncia à polícia ${ }^{10}$.

Contudo, uma dúvida emerge do caso acima relatado. Porque um liberto se deixaria seduzir pelas promessas feitas pelo aliciador de que ele ficaria "liberto no fim de um ano de serviço"? Não parece ser, pelo relato das autoridades policiais, desconhecimento da sua condição de liberto. É possível que o crioulo liberto tenha obtido uma alforria condicional, que obrigava os indivíduos nesta condição a prestarem serviços aos seus senhores, em muitos casos, até a morte destes. Talvez o liberto tenha sido seduzido por uma promessa de alforria plena no final de um ano de serviço, que o tiraria da situação de cativeiro em que a alforria condicional o mantinha. Entretanto, tudo isto não passa de especulação.

Já muitos libertos tiveram uma participação ativa nos furtos de escravos e na sua receptação, às vezes se associando a outros indivíduos. Em 1820, os libertos Ponciano José de Freitas e Maximiliano Nunes foram presos pela polícia "por pegarem em pretos com o título de fugidos, e os irem vender a capitães-de-mato", que atuavam como receptadores. Em 1822, era a vez dos libertos Joaquim da Silva Maia e Manoel Muniz dos Santos serem presos pela polícia, acusados do roubo de uma cativa, A escrava foi vendida por eles a Agostinho Mina, escravo do Padre José Vicente Alves Cruz, que se encontrava fugido há alguns anos de seu senhor e se passava por liberto. Para azar dos dois libertos, o escravo Agostinho foi preso pela polícia e confessou a realização do negócio com eles. Joaquim da Silva Maia e Manoel Muniz dos Santos foram presos, mas antes que isso acontecesse se apropriaram novamente da cativa e a revenderam para um Tenente do Batalhão de Caçadores de nome Estevão, É bem provável que este Tenente soubesse que a escrava era furtada e estivesse atuando como receptador e revendedor de escravos roubados. ${ }^{11}$

Em 1826, o liberto Joaquim Manoel também se envolveria com um militar, o soldado João Francisco, suspeito de deserção, sendo os dois encontrados na freguesia suburbana da Lagoa com uma cativa furtada e presos imediatamente. Já o liberto Januário Angola, que espertamente também usava o nome de Antônio Camundongo, procurou um lugar mais distante na sua

10 Cf. op. cit.. Códice 330, Volume III.

11 Cf. ANRJ, Policia:prisões; 1810-1819, Códice 403, Volume II; e Polícia: ofícios e ordens, op. cit., Códice 330, Volume IV. 
R. História, São Paulo, 120, p.121-133, jan/jul. 1989.

tentativa de vender dois escravos roubados, sendo preso em Jacarepagua (tora da cidade) quando tentava vendê-los à preta liberta Joaquina Maria c ao Desembargador Mariano José de Brito, que parecem ter denunciado o liberto. Em 1845, seria a vez do liberto Domingos Bernardo, de nação Mina e 52 anos de idade, ser preso e condenado a 8 anos de prisão por furto de escravos 12 .

Algumas mulheres libertas também estiveram envolvidas em roubos de escravos. Caso interessante foi o da preta liberta Izabel Maria, presa em 1823 devido à denúncia de Antônio João, morador na Ladeira do Livramento $\mathrm{n}^{2} 35$, de que a liberta seduzira e furtara uma escrava sua de nome Catarina. Izabel Maria, quando foi presa, tinha em seu poder a dita escrava e um escravo do Cônego José do Couto Ribeiro. A polícia apurou ainda que a preta liberta costumava roubar escravos e depois os vendia para um receptador de Minas Gerais de nome Caetano José, que havia sido seu senhor. Uma outra liberta envolvida em roubos de escravos também chamava-se Izabel e fora escrava de dona Candida Rosa de Viterbo. Em 1830, Izabel foi presa pela policia, acusada *'pelo furto e receptação do escravo de nome Joaquim achado em sua casa, escondido dentro de um forno de fazer farinha, no momento de ser ali procurado". Além do escravo Joaquim que já tinha trabalhado com Izabel, quando esta era escrava, um outro cativo de nome Antônia, que a liberta dizia lhe pertencer, foi achado na casa e recolhido à cadeia ${ }^{13}$.

Ainda podemos encontrar participando ativamente de roubos de escravos, outros indivíduos menos suspeitos e que não possuiain "má fama" alguma, como os próprios cidadãos brasileiros civis, militares e até estrangeiros. Acima foi citado o caso de Tenente Estevão, do Batalhão de Caçadores, que comprou de dois libertos uma cativa furtada, podendo ser tranquilamente atuado como receptador e revendedor da escrava furtada. Um outro militai-, o soldado-pedestre João Francisco, preso em 1826 na Lagoa como cúmplice de outro liberto no roubo de uma escrava, parece que conseguiu se livrar da acusação, mas em 1833 seria novamente acusado de furto de escravos. Neste ano, o soldado João Francisco foi acusado por José Machado dos Santos, morador no Rio Comprido, de ter roubado e "conservado em cárcere privado o seu escravo Domingos de Nação Moçambique". O referido escravo andava

12 Cf. ANRJ, Policia: oficios e ordens, op. cit., Códice 330, Volume V; e Casa de Detenção da Corte, Relação de alterações de sentenciados, 1850-1855, IVJ7-1.

13 Cf. ANRJ, Policia; ofícios e ordens, op. cit., Códice 330, Volumes II e V. 
SOARES, Luiz Carlos. O roubo de escravos no Rio de Janeiro e o tráfico interno paralelo: $1808-1850$.

fugido, quando foi preso por um pedestre de nome José Gonçalves Toledo. Este entregou o escravo a João Francisco, que se dirigia ao Calabouço a serviço, para conduzi-lo à dita prisão. Ao invés de entregá-lo, como se sabe, João Francisco conservou o escravo em sua casa para vendê-lo '*a algum dos muitos aliciadores", O pedestre tentou argumentar que não levou o escravo ao Calabouço porque não pudera, mas seus argumentos não foram convincentes e ele foi recolhido à prisão, além de perder o seu posto de pedestre. ${ }^{14}$

Em 1829, Ignacio José, cidadão brasileiro, foi preso pela polícia no cais do Largo do Paço, quando tentava embarcar numa falua, para a Praia Grande, um escravo e uma escrava que ele havia furtado. Em 1836, um Juiz de Paz formou processo contra três cidadãos brasileiros, que se envolveram no roubo e receptaçâo de um escravo. $\mathrm{O}$ autor do roubo teria sido um indivíduo conhecido como F. Guimarães, que vendeu o escravo furtado, por intermédio de um outro chamado Manoel Cornélio, a Manoel Coutinho de Azevedo. ${ }^{15}$

O roubo do escravo João, de Lourenço Justíniano de Brito, praticado pelos portugueses Thomas Ferreira e Pedro Leage em 1830, foi seguido da tentativa engenhosa dos ladrões de tentarem vendê-lo, falsificando documentos de venda, a Antônio Domingos Lobo, morador em São Cristovão. Os portugueses foram presos, quando já estavam concluindo o negócio com Antônio Domingos Lobo, No mesmo ano, a polícia também prendeu os italianos Antonio Barcos e Diogo Maimandolo, o primeiro por roubar a escrava Antônia, de Antônio Ferreira do Nascimento c o segundo por atacar a patrulha que prendera o seu compatriota, a fim de libertá-lo. A mesma desventura teve o francês Joseph Lebuglet que, em 1832, foi preso por uma patrulha no Campo de Santana, na ocasião de oferecer "a uns mineiros escravos a preço de $40 \$ 000$ réis cada um, e que os tinha oculto em uma casa para banda do Saco do Alferes". No ato da sua prisão, o francês, que já tinha sido preso duas vezes por furtos outros e estava '*solto sob fiança", ainda tentou subornar os pedestres da patrulha, oferecendo "dinheiro para o soltarem", I6

A ação de quadrilhas e grupos que se organizavam para roubar escravos e vendê-los fora da cidade também foi muito intensa na primeira metade

14 Cf. ANRJ, Polícia: ofícios e ordem. op. cit., 1829-1833, Códice 330, Volume VI.

15 Cf. ANRJ, Ibidem, Códice 330, Volume VI; c Polícia: correspondência privada, 1833-1840, Códice 334, Volume I.

16 Cf. ANRJ, Polícia: ofícios e ordens, op. cit.. Códice 330, Volumes V e VI. 
R. História, São Paulo, 120, p.121-133, jan/jul. 1989.

do século passado. Frederico Burlamaqui chegou a mencionar a existência de "roubos contínuos de escravos seduzidos por um exército de especuladores", que estavam organizados "sistematicamente para expolíarem aos senhore desta miserável propriedade" ${ }^{17}$. Em 1817, a policia teve conhecimento das ações de uma quadrilha de ladrões de escravos cujo chefe "era um tal de Capitão Gaspar" (indivíduo muito conhecido por seus "muitos títulos"), da qual faziam parte alguns ciganos como os já citados Bento Soares da Rocha e João da Costa. O Capitão Gaspar, além de participar de roubos de escravos e sua receptação, possuía uma organizada rede de distribuição e venda no interior ${ }^{18}$.

A ação das quadrilhas organizadas parece ter sido intensa nos anos 1830, como denunciou Burlamaqui em 1837, Um pouco antes, em 1833, a polícia, através das informações fornecidas por um escravo roubado de nome Francisco, que conseguiu se evadir de seus captores, descobriu as atividades da quadrilha chefiada por um indivíduo de nome Arruda, que morava fora da cidade. A quadrilha se utilizava de um escravo para "seduzir" outros cativos e conduzi-los à casa da amante de Arruda, de nome Maria Luisa, no Catumbi. O escravo "sedutor", cujo nome era Joaquim e pertencia a Francisco João Barboza, recebia 960 réis por cada escravo conduzido à casa de Maria Luisa. Esta depois os repassava para seu amante Arruda, que os levava para Minas Gerais, onde facilmente encontrava compradores ou os entregava a outros receptadores a ele associados. Arruda conseguiu escapar à ação da polícia, mas o escravo Joaquim e Maria Luisa foram presos, sendo encontrados na casa desta um escravo de nome João, cujo senhor era Manoel Fernando de Freitas. Um outro escravo de nação Inhabane foi procurado, mas já tinha sido levado para Minas e vendido ${ }^{19}$.

Uma outra ativa quadrilha se tomou conhecida pela polícia através de uma denúncia anônima. Esta denuncia feita ao Chefe de Polícia Antônio Paulino Limpo de Abreu, em 1835, falava da "existência de uma sociedade, que se [dizia] protegida por pessoas de alta representação", que era "composta de ciganos, e alguns pretos forros" e cuja finalidade exclusiva era o furto de escravos. Os escravos eram "seduzidos" pelos pretos libertos e aprisionados nas suas casas. Estes posteriormente os repassavam para os ciganos, através da venda ou do recebimento de um pagamento por tarefa exe-

17 Cf. BURLAMAQUI. op. cit,, p. 82-83.

18 Cf. ANRJ, - Polícia: ofícios e ordens, op. cit.. Códice 329, Volume IV.

19 Cf. Ibidem, Códice 330, Volume VI. 
SOARES, Luiz Carlos. O roubo de escravos no Rio de Janeiro e o tráfico interno paralelo: $1808-1850$.

cutada. Os ciganos se encarregavam, então, de transportar e vender os escravos furtados fora da cidade. Apesar da denúncia, não há indícios na documentação policial acerea da prisão dos participantes desta quadrilha ${ }^{20}$.

$\mathrm{Na}$ realidade, era muito difícil distinguir se os roubos de escravos eram realizados por quadrilhas ou indivíduos isolados. Estes últimos, quando praticavam os roubos sozinhos, necessitavam de pessoas que receptassem os cativos furtados e os vendessem em outras praças distantes da cidade. Para isso, deve ter existido uma rede muito bem articulada de ladrões, receptadores ou repassado res, que deviam ter suas áreas de influência muito bem delimitadas, e que transformavam todo o roubo, toda a ação, mesmo aquelas mais isoladas, em parte de um esquema maior de comércio paralelo ou marginal de escravos. A existência desta ampla rede toma-se ainda mais provável devido à grande participação dos ciganos em roubos de cativos. Os ciganos, vivendo em comunidades étnica e culturalmente segregadas, encontravam nos laços de solidariedade e parentesco, mantidos nestas comunidades, as bases necessárias para a sua ação organizada no roubo, receptação e venda de escravos $\mathrm{cm}$ outras regiões ${ }^{21}$.

Não podemos esquecer que desta ampla rede do comércio marginal de escravos participavam diretamente membros da polícia e das forças armadas. Sem contar que algumas autoridades policiais, militares e judiciais deviam se deixar '"seduzir" facilmente pelas propinas pagas pelos indivíduos envolvidos no comércio de escravos "roubados", para acobertar suas ações "ilegais". Neste caso, a atitude tias autoridades mencionadas $\mathrm{cm}$ nada se diferenciou da atitude dos seus pares, que participavam do esquema de corrupção montado para permitir o tráfico "ilegal" de escravos africanos depois de 1831.

Outros fatores contribuiram para facilitar a vida dos ladrões de escravos na primeira metade do século XIX. O primeiro deles era a própria geografia da cidade do Rio de Janeiro, cercada de montanhas e densas florestas, que permitiam aos ladrões transpottarern os cativos furtados para fora da cidade sem maiores sobressaltos. O segundo deles se relacionava à ineficiência

20 Cf. ANRJ, Polícia: oficias e ordem, op. cit., Códice 334, Volume I.

21 No início do século XÍX, uma grande parte da comunidade cigana do Rio de Janeiro estava concentrada numa rua da cidade, situada entre o Largo da Lampadosa e o Campo de Santana, que por esta razão foi denominada pelo população. Rua dos Ciganos, tendo o seu nome mudado posteriormente para Rua da Constituição. Cf. COARACY, Vivaldo. Memórias da cidade do Rio de Janeiro. Rio de Janeiro: José Olympic, 1955. p, 466. p. 466. 
R. História, São Paulo, 120, p.121-133, jan/jul. 1989.

do corpo policial que, além de permeável à corrupção, era insuficiente para policiar uma cidade com as dimensões do Rio de Janeiro. Se a capital já era insuficientemente policiada, as estradas que conduziam às províncias do Rio de Janeiro, São Paulo e Minas Gerais o eram ainda mais. Praticamente não existiam nestas estradas postos de controle policia), com exceção das fronteiras provinciais 22 .

O terceiro e mais importante fator da ação dos ladrões de escravos era a grande receptividade que eles encontravam entre alguns senhores, interessados em comprar cativos sem se importarem com a sua procedência. Evidentemente, estes senhores, em sua maioria fazendeiros ou pequenos lavradores, deviam ter conhecimento de que os cativos eram roubados e provavelmente se utilizavam desse conhecimento para conseguir preços mais reduzidos para as "peças" compradas. Para os ladrões e repassadores, que nada investiam na aquisição dos cativos, a não ser as poucas despesas que tinham com o pagamento de aliciadores, alimentação e transporte, a operação de venda era altamente lucrativa, mesmo com os preços abaixo daqueles que vigoravam no mercado "legal" de escravos.

O francês Lebuglet, que, ao ser preso em 1832, oferecia a mineiros escravos por apenas $40 \$ 000$ réis cada um, parece ter exagerado na redução do preço, pois os escravos para trabalhos agrícolas, por exemplo, valiam muito mais. Talvez tenha sido o preço absurdamente baixo que despertou a atenção dos soldados que o prenderam. O inventário post mortem de um pequeno lavrador das cercanias do Rio de Janeiro, de nome José Teixeira Fonseca, falecido no mesmo ano em que o francês foi preso, indica os seguintes valores para escravos de "serviço de roça": uma escrava de 30 anos (Maria) foi avaliada cm 300\$000 réis; um escravo da mesma idade (Luiz) teve o seu valor estipulado em $350 \$ 000$ réis; já um escravo de 60 anos (Antônio) valia apenas 100\$000 réis; existia ainda uma "cria" de 3 anos de idade (Adão Crioulo) avaliado em $100 \$ 000$ réis ${ }^{23}$. Um pouco antes, em 1830, o Jornal do Comércio anunciava a venda, na Rua do Senhor dos Passos $\mathrm{n}^{\circ} 196$, de "uma preta ainda boçal, própria para qualquer serviço" pelo "módico preço de 500 réis" 24.

Para os senhores compradores de escravos roubados, não era nada difícil, nem dispendioso, regularizar a situação destes. Os cartórios do interior,

Cf. PARANAgUÁ, João Lustosa da Cunha. Relatório da Repartição dos Negócios da Justiça apresentado à Assembléia Cerat; Legislativa, Rio de Janeiro, 1860. p. 15 .

23 Cf. ANRJ, Inventário "post-mortem", 1832, Caixa 4,118, n 2.242,

24 Cf. Jornal do Commercío, Rio de Janeiro, 29 de janeiro de 1830. 
SOARES, Luiz Carlos. O roubo de escravos no Rio de Janeira e o tráfico interno paralelo: 1808-1850.

controlados por tabeliães e escrivães facilmente subomáveis, podiam forjar documentos de venda e certidões de propriedade dos cativos adquiridos ilegalmente, mediante uma remuneração não muito elevada. Por isso, e pelo fato de obterem preços mais baratos, fazendeiros e pequenos lavradores correram o risco de comprar escravos roubados.

Porém nos anos 1840, com a intensificação do tranco negreiro africano, os habituais compradores de cativos furtados já não queriam correr mais muitos riscos, pois podiam obter escravos a preços compensadores diretamente nos pontos de desembarque do litoral ou com os traficantes retalhistas, o que muito limitou a ação dos ladrões da propriedade humana. Pode-se argumentar ainda que com o fim do tráfico africano e a grande elevação dos preços dos cativos a partir de 1850 , os ladrões teriam condições de voltar a operar em maior escala, No entanto, justamente por causa da elevação de preços, os senhores não estavam dispostos a fazer altos investimentos na compra de escravos furtados e depois correrem o risco das suas transações serem descobertas pela polícia e terem que devolvê-los a seus proprietários anteriores, respondendo ainda a processo penal. Eles podiam negociar diretamente com os senhores da cidade do Rio de Janeiro que estivessem dispostos a vender os seus escravos, em virtude dos altos preços e do surgimento de novas alternativas para aplicação de seu dinheiro nos anos 1850. Por fim, a própria polícia que, pela Lei Eusébio de Queirós, estava obrigada a reprimir o tráfico africano, teve que prestar mais atenção às atividades daqueles indivíduos que participavam ilegal e marginalmente do tráfico interno de escravos ${ }^{25}$.

Findava, assim, o comércio de escravos roubados entre o Rio de Janeiro e as províncias mais próximas da cidade, comércio este que, mesmo sem o grande volume apresentado pelo comércio "legal", se constituiu numa alternativa paralela ou marginal de obtenção de mão-de-obra tanto pelos grandes fazendeiros como pelos lavradores de menores posses. Não deve ser mera coincidência o fato de termos encontrado apenas algumas poucas e imprecisas referências sobre casos de roubo de escravos na documentação policial consultada relativa à segunda metade do século XIX.

25 Sobre a mudança da atuação policial após a Lei Eusébio de Queirós, ver; BETHEL, Leslie. The abolition of the Brazilian slave trade (Britain, Brazil and the slave trade question; 1807-1869). Cambridge.' Cambridge University Prese, 1970. p. 339-341; e CONRAD, Robert, Tumbeiros. p. 187-188. 
R. História, São Paulo, 120, p.121-133, jan/jul. 1989.

ABSTRACT: Based on police records of the first half of the 19th century, the article studies frequent robbery of slaves in Rio and neighbouring provinces. Points to the coexistence of a more formalized illegal traffic and of a smaller hidden trade in stolen slaves, often controlled by gipsies and their intermediaries. Sometimes led by an individual, sometimes capitães de mato, (bush captain), usually by organized gangs, this illegal trade disappeared after 1850. An interesting aspect $\mathrm{b}$ the frequent involvement of free negroes and their relatives.

UN1TERMS: slave trade, robbery of slaves, bush captain, free negroes, illicit trade. 